\title{
Adult intrarenal neuroblastoma presenting as renal cell carcinoma
}

\author{
Omer Bayrak, MD; ${ }^{*}$ Ilker Seckiner, MD; ${ }^{*}$ Sakip Erturhan; MD; ${ }^{*}$ Abdullah Aydin, MD; Faruk Yagci, MD
}

*Department of Urology, Gaziantep University, Gaziantep, Turkey; ${ }^{\dagger}$ Department of Pathology, Gaziantep University, Gaziantep, Turkey

Cite as: Can Urol Assoc J 2012;6(4):E144-E146. http://dx.doi.org/10.5489/cuaj.11119

\section{Introduction}

Neuroblastoma is known to arise from cells of the neural crest that form the adrenal medulla and sympathetic ganglia. Tumours may occur anywhere along the sympathetic chain within neck, thorax, retroperitoneum, pelvis or in the adrenal gland. Seventy-five percent arise in the retroperitoneum, $50 \%$ in the adrenal, and $25 \%$ in the paravertebral ganglia. ${ }^{1}$ The variety of locations in which these tumours can arise and the spectrum of their differentiation result in a wide range of clinical presentations and behaviours. ${ }^{1}$ These tumours can undergo spontaneous regression, differentiate to benign neoplasm ${ }^{2}$ or exhibit extremely malignant behaviour. ${ }^{3}$

Neuroblastoma has a variable prognosis and is very rarely reported in adults. There are only 3 cases in the English literature on kidney neuroblastoma. We present a case of neuroblastoma in a woman who had an intrarenal mass.

\section{Case report}

A 37-year-old female was referred to our clinic by a nephrologist for evaluation of renal mass. Abdominal ultrasonography showed a $81 \times 61 \mathrm{~mm}$ mass in the right kidney. Her physical examination revealed right upper quadrant mass. She denied significant loss of weight. Urinanalysis demonstrated microscopic hematuria and leucosituria. Laboratory evaluations revealed hemoglobin $12.4 \mathrm{mg} / \mathrm{dL}$, and her creatinine level was $0.61 \mathrm{mg} / \mathrm{dL}$. Computerized tomography (CT) showed a $70 \times 60 \mathrm{~mm}$ regular, heterogen and centrally necrotic mass in the lower pole of the right kidney (Fig. 1, Fig. 2). Both chest radiographs and bone scan showed no evidence of metastatic disease.

The patient had undergone right nephroureterectomy and ipsilateral adrenelectomy with anterior subcostal incision.
There was no adhesion to the adjacent areas and the tumour was removed intact and completely. On gross examination the tumour was $60 \times 60 \times 60 \mathrm{~mm}$ and located in the lower pole. Macroscopically, the tumour was surrounded by the renal capsule and was divided clearly from the normal renal tissue of lower pole. Cut surface of the tumour was yellowish, and necrotic tissue was seen at the centre of the tumour. Microscopically, the tumour was composed of small cells with hyperchromatic nuclei and scanty cytoplasm, arranged as rosettes. For the differential diagnosis, such as primitive neuroectodermal tumours and Wilms' tumour, several immunohistochemistry staining were performed. Tumour cells were reacted with synaptophysin, whereas CD-99, chromogranin, WT-1, neuron specific enolase (NSE) and pancytokeratin were found negative (Fig. 3, Fig. 4, Fig. 5). These microscopic and imunohistochemical findings revealed that this tumour was compatible with neuroblastoma.

The postoperative period was uneventful and the patient was discharged on postoperative day 3 . Bone marrow biopsy was performed on the 45th day after the operation and found normocellular bone marrow. The patient was assumed as stage 1 disease. Six months after the operation, there were no abnormal findings on her CT. The patient received no adjuvant therapy, and she had no evidence of recurrrent residual disease 30 months after surgery.

\section{Discussion}

Neuroblastoma is a rare malignancy with about 500 cases diagnosed each year in the United States. ${ }^{4}$ The incidence is 2.26 per million person-years, with almost all cases diagnosed before the age of 10 years. The incidence rate for patients aged 30 to 39 is 0.2 cases per million person-years, ${ }^{4}$ but kidney neuroblastoma is very rarely reported in adults.

There are no treatment recommendations for neuroblastoma in adults. The treatment modalities in children are surgery, chemotherapy and radiation therapy. The role of each of these modalities varies depending on tumour stage, 


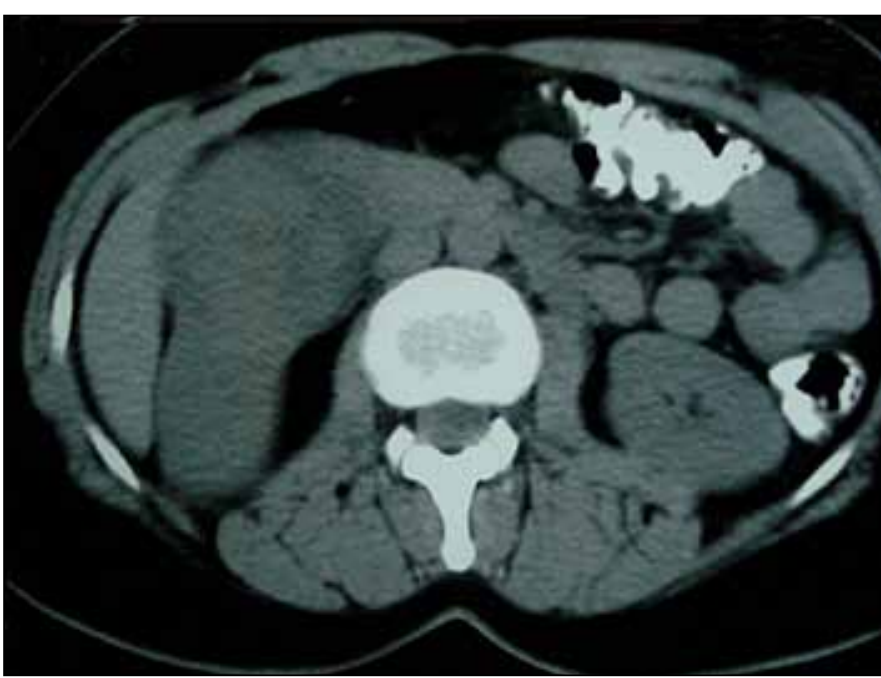

Fig. 1. Axial computerized tomography image of the tumour.

age and biologic prognostic factors. These characteristics can be used to stratify patients into favourable and unfavourable categories by risk group. Children with stage I have a disease-free survival rate of greater than $90 \%$ with surgical excision alone. ${ }^{3}$ Adjuvant therapy (chemotherapy with or without radiotherapy) is reserved for recurrance or higher stage tumours with MYCN amplification and/or unfavourable histologic features. ${ }^{5}$

Primary neuroblastoma of the kidney had not been described in the literature until 1986. Kazuo Gohji and colleagues reported two unusual cases of neoroblastoma of the kidney in adults. ${ }^{6}$ In both patients right radical nephrectomy was performed. Microscopially, both tumours were composed predominantly of scant pink cytoplasm and round nuclei with rosette formation with interspersed fibrils. The first patient received 3000 rad of irradiation to the tumour

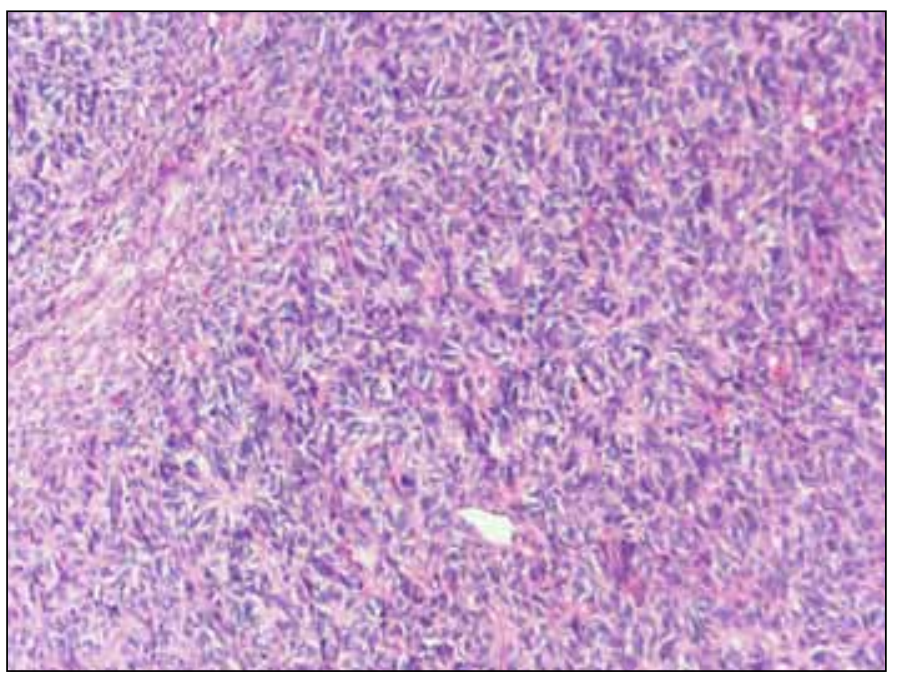

Fig. 3. This microphotograph shows tumour cells with hyperchromatic nuclei and scanty cytoplasms, are concentrically arranged around eosinophilic fibrillary materials (neuropil) (hematoxylin \& eosin stain x 200).

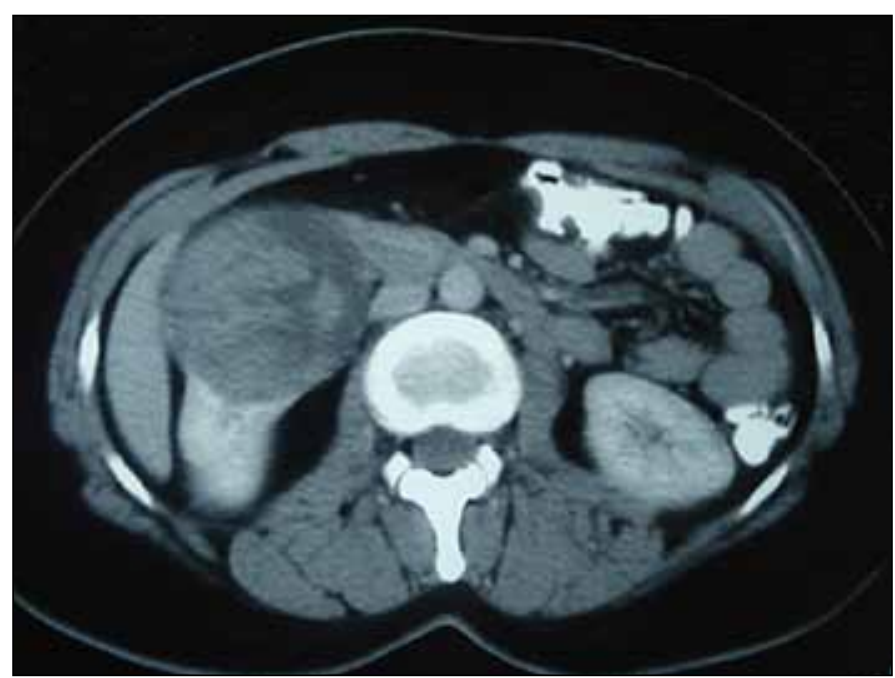

Fig.2. Axial computerized tomography image of the tumour.

bed and para aortic area. There was no evidence of tumour recurrence at follow-up. Progressive disseminated disease was documented in the second patient despite postoperative adjuvant chemotherapy with combined cisplatinum and epipodophyllotoxin, and combined vincristine, cyclophosphamide, doxorubicin and dimethyl-triazeno imidazole carboxamine. Chemotherapy was not effective and the patient's condition gradually worsened. ${ }^{6}$

McLean and colleagues presented the case of a 39-yearold man with stage 1 neuroblastoma with unfavourable histologic features; he was treated with surgery alone. ${ }^{7}$ No treatment recommendations existed for the treatment of neuroblastoma in adults, so they treated this patient according to pediatric guidelines. The patient received no adjuvant therapy, and he had no evidence of recurrrent of residual disease 21 months after surgery. ${ }^{7}$ Like this case, we treated our patient with surgery alone. The patient received no

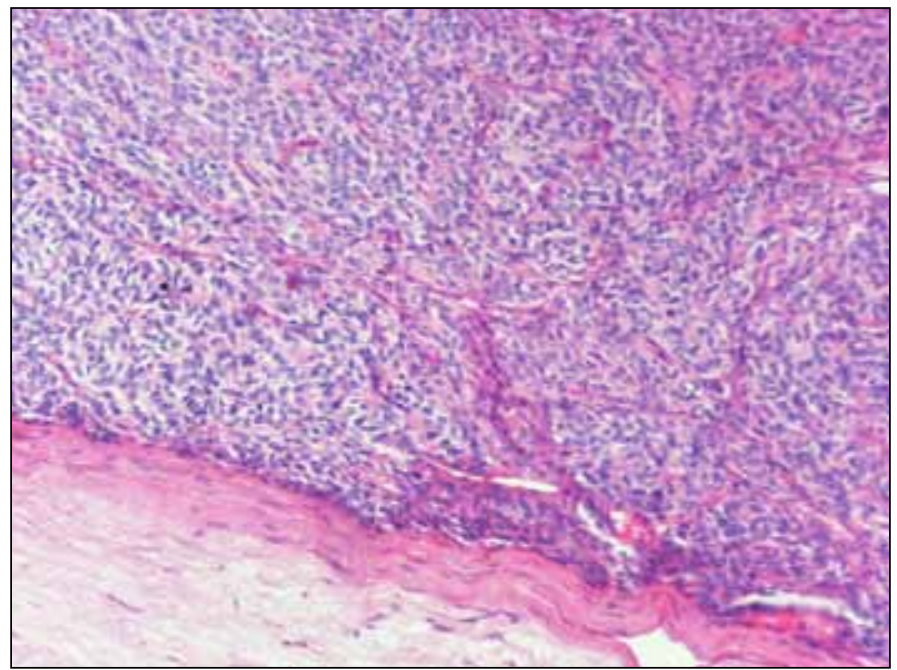

Fig. 4. This picture shows encapsulated circumscribed tumor (hematoxylin \& eosin stain $\times 200$ ). 
Bayrak et al.

\begin{tabular}{|c|c|c|c|c|c|c|}
\hline Cases & Age & Laterality & Tumour size $(\mathrm{cm})$ & $\begin{array}{l}\text { Placement of } \\
\text { tumour in the } \\
\text { kıdney }\end{array}$ & Treatment & Follow-up \\
\hline Case 1, Gohji ${ }^{4}$ & 35 & Right & $15 \times 11 \times 10$ & Lower pole & $\begin{array}{c}\text { Surgery + } \\
\text { radiotherapy }\end{array}$ & No recurrence \\
\hline Case 2, Gohji ${ }^{4}$ & 29 & Right & $28 \times 25 \times 20$ & Upper pole & $\begin{array}{c}\text { Surgery + } \\
\text { chemotherapy }\end{array}$ & $\begin{array}{l}\text { Patient' s } \\
\text { condition had } \\
\text { been gradually } \\
\text { worsening }\end{array}$ \\
\hline Case 3, McLean ${ }^{5}$ & 39 & Right & 9 & Upper pole & Surgery alone & $\begin{array}{l}\text { No recurrence } \\
\text { ( } 21 \text { month after } \\
\text { surgery) }\end{array}$ \\
\hline $\begin{array}{l}\text { Case } 4 \text {, Present } \\
\text { case }\end{array}$ & 37 & Right & $6 \times 6 \times 6$ & Lower pole & Surgery alone & $\begin{array}{l}\text { No recurrence } \\
\text { ( } 30 \text { month after } \\
\text { surgery) }\end{array}$ \\
\hline
\end{tabular}

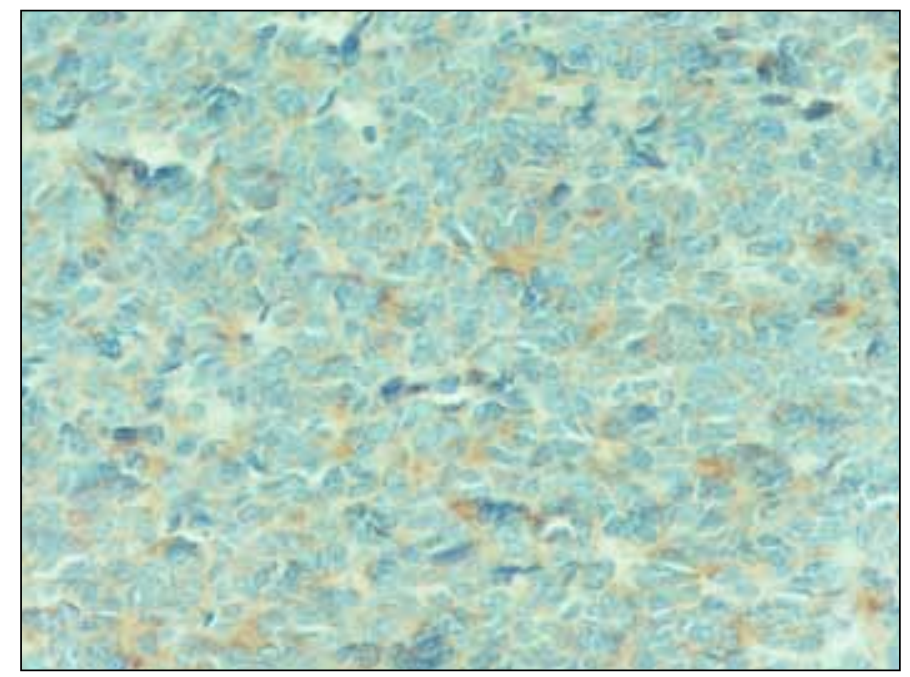

Fig. 5. Immunohistochemical staining revealed that tumour cells, especially neuropil in the centre of rosettes were reacted for synaptophysin (synaptophysin x 200).

adjuvant therapy, and she had no evidence of recurrrent of residual disease 30 months after surgery. Main clinicopathological findings in previously reported cases and our present case are summarized in Table 1.

\section{Conclusion}

Neuroblastoma is extremely rare in adults. There are only 3 cases of kidney neuroblastoma in the literature. However, in patients undergoing radical nephrectomy for renal mass, renal neuroblastoma should be included in the differential diagnosis. If these tumours are limited to the kidney, prognosis is favourable after radical nephrectomy.

Competıng interests: None declared.

This paper has been peer-reviewed.

\section{References}

1. Brodeur GM, Saylors RL. Neuroblastoma, retinoblastoma, and brain tumors in children. Curr Opin Oncol 1991;3:485-96.

2. Cole WH, Everson TC. Spontaneous regression of cancer: preliminary report. Ann Surg 1956;144:366-83.

3. Ritchey M. Pediatric Urologic Oncology, Campbell's Urology. 8th edition;2010:ch. 130.

4. Wester K, Mark S, Smievoll Al. Neuroblastoma and venous sinus thrombosis in an adult patient. Br J Neurosurg 1997;11:241-4. http://dx.doi.org/10.1080/02688699746320

5. Brodeur GM, Maris JM. Neuroblastoma. In: Principles and Practice of Pediatric Oncology. Pizzo PA, Poplack DG (eds); 4th ed. Philadelphia, PA: Lippincott Williams and Wilkins; 2002:895-937.

6. Gohii K, Nakanishi T, Hara I, et al. Two Cases Of Primary Neuroblastoma Of The Kidney In Adults. J Urol 1987;137:966-8.

7. McLean TW, Iskandar SS, Shimada H, et al. Neuroblastoma In An Adult. Urology 2004;64:1232. el8-1232.

Correspondence: Dr. Omer Bayrak, University of Gaziantep, School of Medicine, Department of Urology, 27310 Gaziantep, Turkey; fax: +90 342 3603998; Dromerbayrak@yahoo.com 